\title{
Systemic effects of chronic obstructive pulmonary disease
}

\author{
A.G.N. Agustí*, A. Noguera*, J. Sauleda*, E. Sala*, J. Pons`, X. Busquets
}

\begin{abstract}
Systemic effects of chronic obstructive pulmonary disease. A. G.N. Agustí, A. Noguera, J. Sauleda, E. Sala, J. Pons, X. Busquets. C ERS Journals Ltd 2003.

ABSTRACT: Chronic obstructive pulmonary disease (COPD) is characterised by an inappropriate/excessive inflammatory response of the lungs to respiratory pollutants, mainly tobacco smoking.

Recently, besides the typical pulmonary pathology of COPD (i.e. chronic bronchitis and emphysema), several effects occurring outside the lungs have been described, the socalled systemic effects of COPD. These effects are clinically relevant because they modify and can help in the classification and management of the disease.

The present review discusses the following systemic effects of chronic obstructive pulmonary disease: 1) systemic inflammation; 2) nutritional abnormalities and weight loss; 3) skeletal muscle dysfunction; and 4) other potential systemic effects. For each of these, the potential mechanisms and clinical implications are discussed and areas requiring further research are highlighted.
\end{abstract}

Eur Respir J 2003; 21: 347-360.

\author{
*Servei de Pneumología, ${ }^{\#}$ Analisis \\ Cliniques and "Unidad de Investiga- \\ ción, Hospital Universitari Son Dureta, \\ Palma de Mallorca, Spain.
}

Correspondence: A.G.N. Agustí, Servei de Pneumología, Hospital Universitari Son Dureta, Andrea Doria 55, 07014 Palma de Mallorca, Spain. Fax: 34971175228 E-mail: aagusti@hsd.es

Keywords: Chronic bronchitis, chronic obstructive pulmonary disease, emphysema, inflammation

Received: May 112001

Accepted after revision: August 202002

This study was supported, in part, by Fondo de Investigación Sanitaria, Sociedad Española de Neumología y Cirugía Torácica (SEPAR) and Associació Balear per l'Estudi de les Malalties Respiratories (ABEMAR).
According to the definition of the European Respiratory Society (ERS), chronic obstructive pulmonary disease (COPD) is a disorder characterised by reduced maximum expiratory flow and slow forced emptying of the lungs due to varying combinations of diseases of the airways and emphysema [1]. This definition, as well as those published by many other societies and organisations [2-4], focuses exclusively on the lungs. Thus, it is not surprising that, in the staging and prognosis of the disease, only pulmonary variables such as forced expiratory volume in one second (FEV1) or arterial oxygen tension $\left(\mathrm{Pa}_{\mathrm{a}} \mathrm{O}_{2}\right)$ have been considered and that current therapy targets almost exclusively the lungs [1-4].

This situation is beginning to change since various recent studies have provided evidence that COPD is often associated with significant extrapulmonary abnormalities, the so-called "systemic effects of COPD" (table 1). There is increasing realisation that these systemic effects are clinically relevant and may contribute to better understanding and management of the disease. Exercise limitation, a common complaint in COPD $[1-4]$ and a very significant contributor to the poor quality of life of these patients $[5,6]$, has been traditionally explained by the increased work of breathing and dynamic hyperinflation that result from the airflow limitation characteristic of COPD [1-4]. However, several recent studies have clearly shown that skeletal muscle dysfunction (SMD) is often a very significant contributor to exercise limitation in these patients [7]. The identification of SMD as a major systemic effect of the disease (table 1) has increased interest in skeletal muscle physiology in COPD very significantly and has clearly contributed to a better definition of the role of exercise training [8] and rehabilitation programmes in the clinical management of these patients [9-13]. Other studies have demonstrated that weight loss, another systemic effect of COPD (table 1), is a negative prognostic factor in these patients, independent of other prognostic indices based on the degree of pulmonary dysfunction, such as FEV1 or $\mathrm{Pa}_{\mathrm{a}} \mathrm{O}_{2}[14,15]$. Furthermore, unlike changes in FEV1 and/or $P \mathrm{a}_{2} \mathrm{O}_{2}$, weight loss in COPD is reversible with appropriate therapy, and, whenever this happens, the prognosis improves [14]. The identification of weight loss and SMD as systemic effects of COPD has drawn attention to the importance of nutritional support, often combined with exercise programmes, for the improvement of quality of life and prognosis in these patients [16]. Finally, several recent studies have clearly shown that COPD is associated not only with an abnormal inflammatory response of the lung parenchyma [4] but also with evidence of systemic inflammation, including systemic oxidative stress, activation of circulating inflammatory cells and increased levels of proinflammatory cytokines [17]. 
Table 1. - Systemic effects of chronic obstructive pulmonary disease

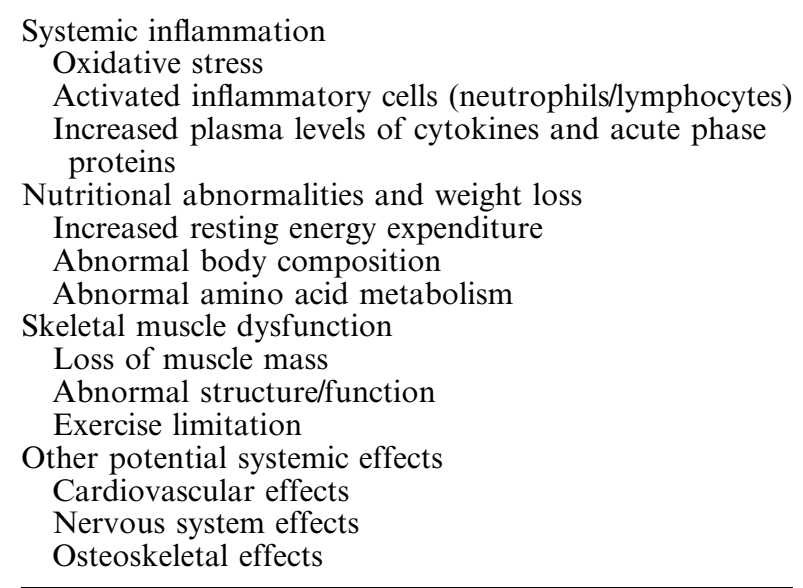

In the present article, current knowledge regarding the extrapulmonary effects of COPD is reviewed and the biological characteristics of the systemic effects identified to date (table 1) and their potential mechanisms and clinical consequences described. Wherever possible, the discussion is based upon available evidence; where evidence is lacking, the authors have provided their opinions as discussion points. Attempts have been made to identify areas that require further research and that could lead to a better understanding of the pathobiology of the systemic effects of COPD. Because of the potential pathogenic role of systemic inflammation in other systemic effects of COPD, this is discussed first.

\section{Systemic inflammation}

It is currently accepted that an excessive/inadequate inflammatory response of the lungs to a variety of noxious inhaled gases or particles (mostly cigarette smoke) is a key pathogenic mechanism in COPD [4]. Various studies have shown that the lung inflammatory response is characterised by: 1) increased numbers of neutrophils, macrophages and T-lymphocytes with a CD8+ predominance; 2) augmented concentrations of proinflammatory cytokines, such as leukotriene $\mathrm{B}_{4}$, interleukin (IL)-8 and tumour necrosis factor (TNF)- $\alpha$, among others; and 3) evidence of oxidative stress caused by the inhalation of oxidants (tobacco smoke) and/or the activated inflammatory cells mentioned above [4]. It is less often realised that similar inflammatory changes can also be detected in the systemic circulation of these patients, including evidence of oxidative stress, the presence of activated inflammatory cells and increased plasma levels of proinflammatory cytokines. This concept is key to understanding the systemic effects of COPD. It will therefore be reviewed in detail here.

\section{Systemic oxidative stress}

The term oxidative stress includes all those functional or structural alterations caused by reactive oxygen species (ROS) [18]. The direct measurement of ROS in vivo is difficult due to their very short half-life [18]. Thus, assessment of ROS levels relies on demonstration of their biological consequences or fingerprints. RAHMAN et al. [19] determined the Trolox-equivalent antioxidant capacity and levels of products of lipid peroxidation in plasma as indices, or fingerprints, of overall oxidative stress in nonsmokers, healthy smokers and COPD patients, during both clinically stable periods and exacerbations of the disease. They found that both indices were significantly increased by smoking and COPD, the latter being particularly significant during episodes of exacerbation [19]. These findings have been confirmed by other investigators using other markers of systemic oxidative stress. Praticò et al. [21] found that urinary levels of isoprostane $F_{2 \alpha}-$ III, a stable prostaglandin isomer formed by ROS-dependent peroxidation of arachidonic acid, which is excreted in urine [20], were higher in patients with COPD than in healthy controls matched for age, sex and smoking habit. Again, differences were more pronounced during exacerbations of the disease [21]. These studies indicate that both smoking and COPD, particularly during exacerbations, are associated with significant systemic oxidative stress $[19,21]$.

\section{Circulating inflammatory cells}

Several studies have shown alterations in various circulating inflammatory cells, including neutrophils and lymphocytes, in COPD, although the former have been more extensively studied in these patients. BURNETT et al. [22] demonstrated that neutrophils harvested from patients with COPD showed enhanced chemotaxis and extracellular proteolysis. In another study, Noguera et al. [23] reported that circulating neutrophils from COPD patients produced more ROS, or "respiratory burst", than those from nonsmokers or healthy smokers, both under basal conditions and after stimulation in vitro. The same authors showed that the level of expression of several surface adhesion molecules, particularly Mac-1 (CD11b), in circulating neutrophils was higher in patients with stable COPD than in healthy controls [24]. Interestingly, this difference disappeared during exacerbations of the disease, suggesting neutrophil sequestration in the pulmonary circulation during exacerbations [24]. In more recent preliminary work, NogUERA et al. [25] showed that the increased expression of CD11b in neutrophils harvested from COPD patients was maintained during the process of neutrophil apoptosis in vitro (compared to healthy controls). As discussed below, this abnormality may be of relevance to the normal process of neutrophil clearance by macrophages from inflamed tissues. Other abnormalities described in circulating neutrophils in COPD include the downregulation of one G-protein subunit (stimulatory $\mathrm{G}_{\alpha}\left(\mathrm{G}_{\alpha \mathrm{s}}\right)$ ) [24]. $\mathrm{G}_{\alpha \mathrm{s}}$ is involved in the intracellular signal transduction pathway linked to CD11b expression [24] and also in the control of intracellular vesicular trafficking [26], the latter being relevant for correct activation of reduced nicotinamide adenine dinucleotide phosphate oxidase, the enzyme eventually responsible for the respiratory 
burst in neutrophils [23]. It is therefore likely that $\mathrm{G}_{\alpha \mathrm{s}}$ plays a role in the regulation of some of the abnormalities described in circulating neutrophils in COPD, namely the increased expression of surface adhesion molecules [24] and the augmented respiratory burst [23].

Circulating lymphocytes have been less well studied than circulating neutrophils in patients with COPD. However, there are some indications of abnormal lymphocyte function in these patients. SAULEDA et al. [27] showed that the activity of cytochrome oxidase, the terminal enzyme in the mitochondrial electron transport chain, was increased in circulating lymphocytes harvested from patients with stable COPD, as compared to healthy nonsmoking controls. Healthy smokers were not included in the study, but this abnormality could also be detected in circulating lymphocytes from patients with other chronic inflammatory diseases, both pulmonary (bronchial asthma) and nonpulmonary (chronic arthritis), suggesting that it may be a nonspecific marker of lymphocyte activation in chronic inflammatory diseases [28]. Interestingly, these investigators also reported the same abnormality (increased cytochrome oxidase activity) in the skeletal muscle of COPD patients [28], the significance of which is discussed below (see Skeletal muscle dysfunction section).

A low $\mathrm{CD} 4+/ \mathrm{CD} 8+$ ratio is a characteristic feature of the pulmonary inflammatory response in COPD [29-33]. Whether this abnormality is mirrored in the systemic circulation in these patients is unclear because the majority of studies addressing this issue compared peripheral T-cell subsets in smoking and nonsmoking subjects and did not include patients with COPD [34-36]. Miller et al. [34] did not find any significant difference in the total number of T-lymphocytes and T-cell subsets in light or moderate smokers compared with nonsmokers, but reported that numbers of circulating CD8+ T-cells were increased and CD4+ cells decreased in heavy smokers; interestingly, these changes disappeared 6 weeks after smoking cessation. Similarly, Costabel et al. [35] did not find significant differences in the proportion of CD4+ and CD8+ lymphocytes in the systemic blood of young healthy smokers, as compared to healthy nonsmokers, despite obvious differences in bronchoalveolar lavage fluid. Finally, EKBERG-JANSSON et al. [36] reported changes in the number of "activated" T-cells (using CD57+ and CD28+ as markers of activation) in the peripheral blood of healthy smokers compared to nonsmokers. Overall, the results of these studies seem to indicate that cigarette smoking can cause alterations in the number of circulating immunoregulatory T-cells, probably reversible after quitting smoking [34]. Whether this is also the case for COPD is less clear. In order to separate the role of smoking from that of COPD, DE JoNG et al. [37] investigated lymphocyte subsets in the peripheral blood of (smoking and nonsmoking) COPD patients and (smoking and nonsmoking) healthy control subjects. They could not find significant differences in lymphocyte subsets when either total groups or smoking subjects of both groups were compared. However, the percentage of CD8+ lymphocytes was significantly higher in nonsmoking COPD subjects than nonsmoking healthy controls [37]. Further, these authors showed that, within the group of nonsmoking COPD subjects, a higher CD4+/CD8+ ratio in peripheral blood was associated with better lung function [37]. Whether these findings represent a consequence of the disease, i.e. spillover of the pulmonary inflammatory process, or a potential pathogenic mechanism, which maybe related to susceptibility to COPD development in some smokers, is unknown. However, it should be borne in mind that the $\mathrm{CD} 4+/ \mathrm{CD} 8+$ ratio is genetically controlled in humans [38] and it could be hypothesised that a genetically determined, low CD4+/CD8+ ratio may render a smoker more susceptible to developing COPD. Investigation into this issue would be relevant to a better understanding of the pathogenesis of the disease.

\section{Increased plasma levels of proinflammatory cytokines}

Numerous studies have reported increased levels of circulating cytokines and acute phase reactants in the peripheral circulation of patients with COPD [39-43]. Abnormalities include increased concentrations of TNF- $\alpha$, its receptors (TNFR-55 and TNFR-75), IL-6, IL-8, C-reactive protein, lipopolysaccharide-binding protein, Fas and Fas ligand [39-43]. These abnormalities were seen in patients considered clinically stable, but were generally more pronounced during exacerbations of the disease [42]. It is interesting to note here that a very similar cytokine profile, including increased levels of IL-6, IL-1 $\beta$ and granulocyte-macrophage colonystimulating factor (GM-CSF), has been described recently in healthy subjects during the South-East Asian haze of 1997 [44]. This observation suggests that the pulmonary inflammatory response to particulate air pollutants (particles with a 50\% cut-off aerodynamic diameter of $10 \mu \mathrm{m})$ is also associated with a systemic inflammatory response [44], like that seen in patients with COPD [42]. Finally, other authors have shown that peripheral monocytes harvested from patients with COPD are capable of producing more TNF- $\alpha$ when stimulated in vitro than those obtained from healthy controls [45]. This was particularly evident in patients with COPD and low body weight, suggesting that excessive production of TNF- $\alpha$ by peripheral monocytes may play a role in the pathogenesis of weight loss in COPD (see Nutritional abnormalities and weight loss section) [45].

The mechanisms of systemic inflammation in COPD are unclear but several, not mutually exclusive, mechanisms could be operative. First, tobacco smoke alone can cause, in the absence of COPD, significant extrapulmonary diseases, e.g. coronary artery disease. Young smokers and even passive smokers may present with endothelial dysfunction of the systemic vessels [46, 47] and systemic oxidative stress [20]. Clearly, tobacco smoking has the potential to contribute to systemic inflammation in COPD. A second potential mechanism is that the pulmonary inflammatory process in the lung in COPD is the source of the systemic inflammation. Inflammatory lung cells release inflammatory cytokines, such as TNF- $\alpha$, IL-6, IL-1 $\beta$, macrophage inflammatory protein $1 \alpha$ and GM-CSF, and increase 
oxidant production on interaction with atmospheric particles, necrotic cells and other inflammatory mediators [44]. These proinflammatory mediators may reach the systemic circulation and/or contribute to the activation of inflammatory cells during transit through the pulmonary circulation. A third possibility is that some of the abnormalities described in the peripheral circulation of patients with COPD (e.g. the increased surface expression of several neutrophil adhesion molecules (CD11b) and downregulation of G-protein subunits $\left.\left(G_{\alpha s}\right)[24]\right)$ may be a cause rather than a consequence of COPD. This possibility is based upon the following observations. Only a percentage of smokers eventually develop COPD [48], suggesting the participation of other factors, probably genetic, in the pathogenesis of the disease [49]. It is possible that the neutrophil abnormalities seen in COPD could be the expression of a genetic predisposition that render these cells more susceptible to the effects of smoking or other proinflammatory agents. These cells could then exhibit a more vigorous response to the same degree of stimulation, including greater expression of surface adhesion molecules, which would facilitate their recruitment to the site of inflammation [24], and an increased respiratory burst that would enhance their damaging potential [23]. However, because it is still not known whether these abnormalities can be seen in susceptible smokers before they develop COPD, the potential role of these three mechanisms warrants further investigation.

\section{Nutritional abnormalities and weight loss}

Various studies have described the presence of nutritional abnormalities in patients with COPD. These include alterations in caloric intake, basal metabolic rate, intermediate metabolism and body composition [50-53]. The most obvious clinical expression of these nutritional abnormalities is unexplained weight loss. This is particularly prevalent in patients with severe COPD and chronic respiratory failure, occurring in $\sim 50 \%$ of these patients [51], but can be seen also in $\sim 10-15 \%$ of patients with mild-to-moderate disease [51].

Loss of skeletal muscle mass is the main cause of weight loss in COPD, whereas loss of fat mass contributes to a lesser extent [51]. Importantly, however, alterations in body composition can occur in COPD in the absence of clinically significant weight loss [43, $50,51]$. The detection of these more subtle alterations requires the use of sophisticated technology, such as dual-energy X-ray absorption or bioelectrical impedance measurements $[16,54,55]$. Using this technology, ENGELEN et al. [56] were able to show significant differences in body composition (lean mass, fat mass and bone mineral content) between not only patients with COPD and healthy volunteers but also COPD patients with predominantly chronic bronchitis and COPD patients with predominantly emphysema, classified by the usual clinical criteria and high-resolution computed tomographic findings.

The terms "malnourishment" and "cachexia" are often used indiscriminately in discussion of the nutritional abnormalities in COPD; however, important differences exist between these terms. As shown in table 2, both terms share several biochemical characteristics, but their origin and, importantly, response to dietary supplementation are very different. Several observations suggest that patients with COPD may suffer from cachexia rather than malnourishment. For instance, the caloric intake of patients with COPD is normal or even greater than normal, not lower, as in malnourishment; their metabolic rate is usually increased, whereas it is decreased in malnourished patients [57, 58]; and their response to nutritional support is often poor $[59,60]$.

The causes of these nutritional abnormalities are unclear. As mentioned above, decreased caloric intake does not appear to be very prominent in these patients, except during episodes of exacerbation of their disease [61]. In contrast, most patients with COPD exhibit an increased basal metabolic rate and, because this increased metabolic requirement is not met by a parallel increase in caloric intake, weight loss ensues [61]. The cause of the increased basal metabolic rate is also unclear. Traditionally, it has been explained on the basis of an increased oxygen consumption $\left(V^{\prime} \mathrm{O}_{2}\right)$ of the respiratory muscles due to the increased work of breathing that characterises the disease [62]. However, it has been recently shown that skeletal nonrespiratory muscle $V^{\prime} \mathrm{O}_{2}$ is higher at any given load in patients with COPD than in age-matched healthy controls [63], indicating that bioenergetic abnormalities are also present in nonrespiratory muscles, and that these abnormalities probably contribute to the increased metabolic rate in patients with COPD [8, 64-68].

Several mechanisms could conceivably contribute to the increased metabolic rate in COPD. First, drugs commonly used in the treatment of COPD (e.g. $\beta_{2}$-agonists) can increase metabolic rate [69]. Secondly, systemic inflammation could also play a significant role, as shown by the relationship between metabolic derangement and increased levels of inflammatory mediators in COPD [40]. Thirdly, tissue hypoxia may also make a contribution [70], since other diseases characterised by tissue hypoxia, such as congestive heart failure, also show increased metabolic rate [71]. Further, a direct relationship between the activity of

Table 2. - Comparison of malnourishment and cachexia

Malnourishment

Cachexia

Fat triglyceride content

Skeletal muscle protein content

Origin

Response to dietary supplementation

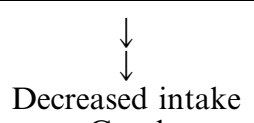

Good

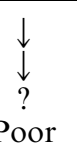

Poor

$\downarrow$ : very reduced. 
cytochrome oxidase, the mitochondrial enzyme that consumes oxygen, in skeletal muscle and the degree of arterial hypoxaemia present in COPD has been found [28]. Similar upregulation of cytochrome oxidase was also found in circulating lymphocytes harvested from patients with COPD [27], suggesting that this bioenergetic abnormality may affect tissues other than skeletal muscle.

Weight loss is an important prognostic factor in COPD patients, and their prognostic value is independent of that of other prognostic indicators, such as FEV1 or $\mathrm{Pa}, \mathrm{O}_{2}$, which assess the degree of pulmonary dysfunction $[14,15]$. Therefore, weight loss constitutes a new systemic domain of COPD not considered by traditional measures of lung function. Further, ScHOLS et al. [14] showed that the prognosis improved in patients with COPD if body weight could be regained after appropriate therapy, despite the absence of changes in lung function. Therefore, these data indicate that the clinical assessment of patients with COPD should take into consideration, along with the severity of the lung disease $[1,2]$, the extrapulmonary systemic consequences of COPD, of which weight loss is of paramount importance [72]. In this context, CELLI et al. [72] showed that a composite score that included different domains of the disease (FEV1, body weight, exercise capacity, perception of symptoms, etc.) was able to predict utilisation of healthcare resources in patients with COPD much better than FEV1 alone. This approach may have significant health economics implications and could serve to evaluate the outcome of different therapeutic interventions in a more comprehensive way than the traditional methods, based mainly on FEV1.

\section{Skeletal muscle dysfunction}

COPD is characterised by a pathological rate of decline in lung function with age, and, as a result, patients with COPD often complain of dyspnoea and exercise intolerance [73]. The concept that exercise intolerance in COPD was due to dyspnoea, in turn caused by the increased work of breathing secondary to airflow obstruction, was first challenged by KILLIAN and coworkers [74, 75], who showed that many patients with COPD stop exercise because of leg fatigue rather than dyspnoea. This observation was probably the first indication that skeletal muscle was abnormal in COPD and strongly stimulated research in the field. Several publications have now confirmed that SMD is common in patients with COPD, and that it contributes significantly to limiting their exercise capacity and quality of life [7, 76]. Interestingly, the respiratory muscles, particularly the diaphragm, appear to behave quite differently from skeletal muscles in these patients, from both structural and functional points of view [7], probably due to the very different conditions under which both work in these patients, the skeletal muscles being generally underused whereas the diaphragm is constantly working against an increased load [77, 78]. Discussion of this topic, however, exceeds the scope of the present review and so is not discussed further.

Despite the fact that SMD is probably the systemic effect of COPD most extensively studied, its mechanisms are still poorly understood. It is important to realise that SMD in COPD is probably characterised by two different, but possibly related, phenomena: 1) net loss of muscle mass, an intrinsic muscular phenomenon; and 2) dysfunction or malfunction of the remaining muscle. Muscle malfunction may be secondary to either intrinsic muscle alterations (mitochondrial abnormalities and loss of contractile proteins) or alterations in the external milieu in which the muscle works (hypoxia, hypercapnia and acidosis), resulting from the abnormalities of pulmonary gas exchange that characterise COPD [79]. Although conceptually important, the separation of these two aspects of SMD is extremely difficult in vivo and both probably play some role in any given patient. With this caveat in mind, the text that follows discusses potential mechanisms of SMD in COPD (table 3).

\section{Sedentarism}

Due to shortness of breath during exercise, patients with COPD often adopt a sedentary lifestyle. Physical inactivity causes net loss of muscle mass, reduces the force generating capacity of muscle and decreases its resistance to fatigue [80]. Exercise training improves muscle function in COPD patients [8, 63, 81, 82], indicating that sedentarism is likely to be an important contributor to SMD. However, complete normalisation of muscle physiology is often not fully achieved after rehabilitation, and, more importantly, some of the biochemical abnormalities found in muscles are unlikely to be explained by physical inactivity. For instance, the increased activity of cytochrome oxidase observed in the skeletal muscle of patients with COPD (and discussed above in the context of the increased metabolic rate in COPD) cannot be explained by sedentarism, which is characterised by decreased, not increased, cytochrome oxidase activity [28]. Further, this same abnormality occurs in circulating lymphocytes [27], and, given that these cells are not influenced by inactivity and detraining, other explanations are required (see below). Finally, at variance with the normal training response, exercise in patients with COPD enhances the release of amino acids, particularly alanine and glutamine [52], from skeletal muscle, suggesting the presence of intrinsic muscle abnormalities of intermediate amino acid metabolism [53].

Table 3.-Potential mechanisms of skeletal muscle dysfunction in chronic obstructive pulmonary disease

\section{Sedentarism}

Nutritional abnormalities/cachexia

Tissue hypoxia

Systemic inflammation

Skeletal muscle apoptosis

Oxidative stress

Abnormal nitric oxide regulation

Tobacco

Individual susceptibility

Hormone alterations

Electrolyte alterations

Drugs 


\section{Tissue hypoxia}

Several observations support a potential pathogenic role for tissue hypoxia in the development of SMD in COPD. First, chronic hypoxia suppresses protein synthesis in muscle cells, causes net loss of amino acids and reduces expression of myosin heavy chain isoforms $[83,84]$. Secondly, healthy subjects at high altitude (hypobaric hypoxia) lose muscle mass [85, 86]. Thirdly, skeletal muscle from patients with COPD and chronic respiratory failure exhibits structural (decrease of type I fibres [87, 88]) and functional (upregulation of mitochondrial cytochrome oxidase [28]) alterations proportional to the severity of arterial hypoxaemia. If tissue hypoxia plays a pathogenic role, domiciliary oxygen therapy may have a beneficial effect upon SMD in COPD. This possibility should be addressed in further studies.

\section{Systemic inflammation}

Systemic inflammation is likely to be an important pathogenetic mechanism of SMD in COPD. As discussed above, COPD patients show increased plasma levels of a variety of proinflammatory cytokines, particularly TNF- $\alpha$ [39-41, 43, 89]. Also, circulating monocytes harvested from such patients produce more TNF- $\alpha$ in vitro than those from healthy controls [45], and several authors have now shown increased plasma concentrations of soluble $\mathrm{TNF}-\alpha$ receptors $[40,41,43]$. TNF- $\alpha$ can affect muscle cells in a number of ways [90]. In differentiated myocites studied in vitro, TNF- $\alpha$ activates the transcription factor nuclear factor $-\kappa \mathrm{B}$ and degrades myosin heavy chains through the ubiquitin/proteasome complex (U/P) [90]. Several studies have now shown that dysregulation of the U/P system contributes to the loss of muscular mass caused by sepsis or tumours in rats [91]. Whether this also occurs in COPD patients has not yet been investigated. Alternatively, TNF- $\alpha$ can induce the expression of a variety of genes, such as those encoding the inducible form of nitric oxide synthase (iNOS), TNF- $\alpha$ itself and many other proinflammatory cytokines, that would create a closed loop and contribute to the persistence and amplification of the inflammatory cascade [90]. Finally, TNF- $\alpha$ can induce apoptosis in several cell systems [92]. It has recently been shown that excessive apoptosis of skeletal muscle occurs in patients with COPD and weight loss [93]. Increased levels of circulating TNF- $\alpha$ and increased apoptosis of skeletal muscle cells have also been described recently in patients with chronic heart failure [94, 95], suggesting that this mechanism may be operating in other chronic diseases and not be unique to COPD [76]. Given that cytochrome c release from the mitochondria is an early event in apoptosis $[96,97]$ and that the activity of cytochrome oxidase is increased in COPD patients [28], mitochondrial abnormalities could play a mechanistic role in this context. This should be examined carefully, since a better understanding of the molecular pathways controlling this phenomenon may lead to the development of new therapeutic alternatives for these patients [98].

\section{Oxidative stress}

As discussed above, patients with COPD exhibit oxidative stress in their systemic circulation, particularly during exacerbations of their disease [19], that could also be relevant to the pathogenesis of SMD [99]. Oxidative stress causes muscle fatigue [100] and facilitates proteolysis $[91,101]$. This might be particularly relevant since regulation of glutathione, the most important intracellular antioxidant [99], is abnormal in the skeletal muscle of patients with COPD [102]. Finally, oxidative stress is an important contributor to the normal process of ageing characterised by, among other things, loss of muscle mass [103, 104]. Whether or not a premature and/or accelerated ageing process occurs in COPD patients with SMD has not been explored to date, but this possibility is currently being investigated by the present authors.

\section{Nitric oxide}

Nitric oxide is a free radical synthesised from the amino acid L-arginine by the action of three nitric oxide synthases (NOS) [105], all of which are expressed in human muscle [106]. Two NOS isoforms, the socalled type I neuronal or brain NOS and type III or endothelial NOS, are expressed constitutively, whereas the third isoform, type II NOS or iNOS, is expressed in response to a variety of stimuli, including cytokines, oxidants and/or hypoxia [106]. The role of NO in the pathogenesis of SMD in COPD is unclear, but it could play a mechanistic role through several, not mutually exclusive, pathways. First, given that the number of capillaries in the skeletal muscle of patients with COPD is lower than normal [107], it is conceivable that endothelial NOS expression is also reduced. This could contribute to jeopardising control of the microcirculation and supply of oxygen to working muscle, eventually resulting in tissue hypoxia (see above). Secondly, systemic inflammation can upregulate the expression of iNOS in skeletal muscle [108]. Preliminary results suggest that this occurs in COPD patients who loose weight [109]. In turn, the increased NO production resulting from iNOS upregulation can cause protein nitrotyrosination and facilitate protein degradation through the U/P system [91] and/or enhance skeletal muscle apoptosis [110]. Results indicate that both do indeed occur in patients with COPD and low body weight [93, 109]. Finally, iNOS induction can also cause contractile failure [111], thus potentially limiting exercise tolerance in these patients.

\section{Tobacco smoke}

Although it is accepted that tobacco smoke is the main risk factor for COPD [73], much less attention has been paid to the potential effects of tobacco smoke upon skeletal muscle structure and function in these patients. However, tobacco smoke clearly reaches the systemic circulation, as shown by the increased prevalence of coronary artery disease and endothelial dysfunction in smokers $[46,47]$, and contains many substances 
potentially harmful to skeletal muscle. For instance, nicotine alters the expression of important growth factors, such as TGF- $\beta 1$, involved in the maintenance of muscular mass [112] and competes with acetylcholine for its receptor at the neuromuscular junction, thus having the potential to affect muscle contraction directly [113]. Therefore, it is possible that tobacco smoke may also contribute to SMD in COPD; this should be investigated.

\section{Individual susceptibility}

It is now accepted that chronic smoking is necessary but not sufficient to cause COPD since only a percentage of smokers develop COPD [73]. A similar, but not as widely recognised concept is the fact that not all patients with COPD lose muscle mass during the course of their disease [51]. Although this may be related to severity [51] or phenotype of disease [56], a genetic component similar to that suggested to explain the development of COPD in only a proportion of smokers $[114,115]$ cannot be excluded. The genes potentially involved in this process are unknown. Some potential candidate genes include those encoding for the angiotensin-converting enzyme (ACE), several transcription factors (myogenic basic helix-loop-helix gene D (MyoD) and myocyte-enhancer factor (MEF)-2) and proteins related to the process of histone acetylation/ deacetylation (cyclic adenosine monophosphate responsive element-binding protein (CBP)/p300 and histone deacetylase (HDAC)5). The ACE gene is known to influence the muscular response to training in athletes [116] and the development of right ventricular hypertrophy in patients with COPD [117]. Further, a very recent report has shown that use of ACE inhibitors can reduce the normal decline in muscle mass that occurs during ageing and improve exercise capacity [118], thus raising the possibility of using these drugs therapeutically in patients with COPD and weight loss. MyoD and MEF-2, as well as CBP/p300 and HDAC5, have very recently been shown to play a fundamental role in the failure of muscle cells to regenerate after injury in patients with cancer cachexia $[119,120]$. Whether they play any role in the pathogenesis of SMD in patients with COPD has not been explored. In summary, the potential role of a genetic background predisposing some COPD patients to the development of SMD is unclear but deserves further investigation. The new microarray technology $[121,122]$ is currently being used to investigate differential gene expression in the skeletal muscle of patients with COPD with and without weight loss [123].

\section{Other mechanisms}

There are other potential mechanisms that, alone or in combination, could contribute to SMD in patients with COPD. For instance, the regulation of several hormone pathways seems altered in patients with COPD, including findings of low testosterone and growth hormone levels $[124,125]$ and reduced plasma leptin concentration [126-128]. All of these are potentially important in the control of muscle mass and body weight and may therefore contribute to the abnormal amino acid metabolism described in the skeletal muscle of patients with COPD $[52,53]$. Likewise, for a variety of reasons (diet, inactivity and drug therapy), abnormal plasma electrolyte values, such as low concentrations of potassium, phosphorus, calcium and magnesium, are not uncommon in patients with COPD and can also cause contractile dysfunction and muscle weakness [129-132]. A recent position paper issued jointly by the ERS and the American Thoracic Society indicates that administration of ionic supplements, when necessary, can improve muscle function in these patients [7]. Finally, many of the drugs used in the treatment of COPD can also interfere with skeletal muscle function. For instance, $\beta_{2}$-adrenergic drugs cause increased oxygen consumption [69], a condition that by itself can cause oxidative stress, and treatment with oral corticoids can cause skeletal muscle weakness in patients with COPD [133-136] and, more importantly, also seems to jeopardise their prognosis, as shown by a very recent population-based cohort study of 22,620 individuals carried out in Canada [137]. In this study, after adjusting for age, sex, comorbidity, treatment and previous emergency visits for COPD, treatment with oral steroids significantly increased all-cause mortality and the risk of repeated hospitalisation in patients with COPD [137]. Whether this observation is a marker of disease severity or truly reflects an undesired systemic effect is unclear due to the retrospective nature of the study. However, it agrees with previous observations supporting a negative effect of oral steroid treatment upon skeletal muscle in COPD patients [133-136].

SMD in COPD has two obvious consequences: 1) it contributes significantly to weight loss [51], a poor prognostic factor in these patients [14, 15]; and 2) it is one of the main causes of exercise limitation [7], having a profound impact on quality of life [5, 138]. Thus, appropriate treatment of SMD should be a priority in the clinical management of COPD [7]. Currently, this is based mostly upon rehabilitation programmes, nutritional support and, perhaps, oxygen therapy [9-11, 13, 43, 76, 139]. However, more specific and effective therapies need to be developed. In this context, the use of anabolic steroids is a potentially effective treatment whose use in SMD should be better delineated [14]. Since TNF- $\alpha$ might be a biological mediator of SMD in COPD, it could be speculated that the use of antibodies directed against TNF- $\alpha$ may be beneficial in these patients. These antibodies have been effective in the treatment of other chronic inflammatory diseases, such as rheumatoid arthritis, in which TNF- $\alpha$ plays a key pathogenic role [140-145]. This therapeutic approach should be explored.

In summary, the cellular mechanisms of SMD in COPD are not clearly understood, but probably result from the combination of several complex and interrelated factors (table 3). Many of these mechanisms may not be exclusive to COPD and may also play an important role in other chronic diseases, such as cardiac and renal failure, cancer and acquired immune deficiency syndrome [76]. Like patients with COPD, patients with chronic heart failure also lose skeletal 
muscle mass during the course of their disease [76], and the skeletal muscle of patients with chronic heart failure exhibits similar histopathological abnormalities to those reported in COPD [76], including increased apoptosis [146]. Finally, the mechanisms cited to explain these abnormalities are very similar to those discussed above for COPD, and include inactivity, tissue hypoxia, oxidative stress and systemic inflammation [76]. Thus, it is very likely that SMD may not be unique to COPD but represent a final pathway common to several chronic diseases. If so, this would further strengthen the importance of investigating and eventually revealing the molecular mechanisms underlying it because, by doing so, new potential therapeutic avenues may be opened up for many chronic debilitating diseases, including COPD.

\section{Other potential systemic effects of chronic obstructive pulmonary disease}

Besides the currently accepted systemic effects described above, systemic inflammation, nutritional abnormalities and SMD, other organ systems might also be affected by the systemic influences of COPD.

\section{Cardiovascular effects}

Coronary artery disease is not rare in patients with COPD because both diseases share similar risk factors, such as cigarette smoking, increased age and inactivity. However, in the absence of coronary artery disease and overt cor pulmonale, it is presently unclear whether or not left ventricular function is normal in stable patients with COPD [147]. Since cardiac output appears to increase normally during exercise, even in severe COPD [147], the link between cardiac output and $V^{\prime} \mathrm{O}_{2}$ seems preserved. However, at peak exercise, cardiac output is $\sim 50 \%$ of what a normal subject of the same age could achieve by reaching a higher $V^{\prime} \mathrm{O}_{2}$ [147]. Two potential explanations are possible for this finding. First, the regulation of cardiac output during exercise in lung disease may remain so tight that, despite the capacity for a higher cardiac output, it matches the level of exercise (and thus, $V^{\prime} \mathrm{O}_{2}$ ) achieved [147]. The second more intriguing possibility is that, despite the absence of overt heart failure, left ventricular function may be compromised in COPD and a higher cardiac output may not be achievable. Although this possibility is speculative, it may merit further study since similar mechanisms to those described for skeletal muscle may be operative in the myocardium [148-151].

The endothelium is no longer seen as a passive barrier but as a very active tissue with key physiological functions in the control of vascular tone and tissue perfusion [105]. In resected lung specimens studied in vitro, it has been shown that endothelial function is abnormal in COPD [152]. The use of Doppler echocardiographic technology has allowed the noninvasive study of endothelial function in other vascular territories in vivo [46, 47, 153]. It has been shown that in patients with COPD, the endothelial function of the renal circulation is also abnormal [154, 155]. Whether or not this abnormality may also occur in other systemic vascular territories is not known at present.

\section{Nervous system effects}

Various aspects of the nervous system may be abnormal in patients with COPD. For instance, the use of nuclear magnetic resonance spectroscopy has shown recently that the bioenergetic metabolism of the brain is altered in these patients [156]. Whether this represents a physiological adaptation to chronic hypoxia, as occurs at altitude [157], or whether it may be considered another systemic effect of COPD mediated by other unknown mechanisms is unclear.

Another potential systemic effect of COPD upon the central nervous system relates to the high prevalence of depression reported in these patients [158-160]. It is possible that this may simply represent a physiological response to chronic debilitating disease. However, it is equally plausible that it may bear some relationship to the systemic inflammation that occurs in COPD, since TNF- $\alpha$ and other cytokines and molecules, such as nitric oxide, have been implicated in the pathogenesis of depression in several experimental models [161-163]. Better delineation of these issues may open new therapeutic possibilities in COPD.

Finally, some recent data suggest that the autonomic nervous system may also be altered in patients with COPD [164]. TAKABATAKE et al. [164] showed indirect evidence of abnormal autonomic nervous system control in patients with COPD, particularly those with low body weight, and a related deregulation of the normal circadian rhythm of leptin. Given that leptin has important effects on neuroendocine function, appetite regulation, body weight control and thermogenesis in humans [164], and that previous studies have shown reduced plasma leptin concentrations in patients with COPD [126-128], these findings may well also be relevant to the pathogenesis of SMD and weight loss in COPD.

\section{Osteoskeletal effects}

The prevalence of osteoporosis is increased in patients with COPD $[165,166]$. Osteoporosis can have multiple causes, singly or in combination, including malnutrition, sedentarism, smoking, steroid treatment and systemic inflammation [166-168]. Since most of them are already considered potential pathogenic factors of SMD in COPD, they could theoretically also contribute to osteoporosis, and, in this context, excessive osteoporosis in relation to age could also be considered a systemic effect of COPD [56]. It is interesting to note that emphysema and osteoporosis are both characterised by net loss of lung or bone tissue mass and, pictorially, an osteoporotic bone looks quite similar to an emphysematous lung! It is therefore tempting to speculate that the two conditions might share common mechanisms to explain the accelerated loss of tissue mass or its defective repair. This intriguing 
possibility merits further study because better understanding of the causes of the "excessive" osteoporosis of COPD may allow the design of new therapeutic alternatives that, eventually, may contribute to palliating its symptoms and reducing the associated healthcare costs [169].

\section{Conclusions}

The studies discussed in the present review clearly support the concept that chronic obstructive pulmonary disease can no longer be considered a disease affecting the lungs alone. The available evidence indicates that: 1) chronic obstructive pulmonary disease has an important systemic component; 2) clinical assessment of chronic obstructive pulmonary disease ought to take into consideration the systemic components of the disease; and the treatment of these extrapulmonary effects appears to be important in the clinical management of the disease. A better understanding of the systemic effects of chronic obstructive pulmonary disease may permit new therapeutic strategies that might result in a better health status and prognosis for these patients.

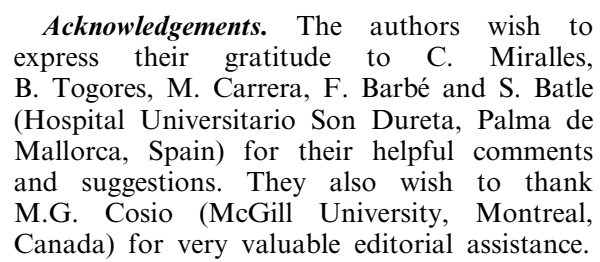

\section{References}

1. Siafakas NM, Vermeire P, Pride NB, et al. Optimal assessment and management of chronic obstructive pulmonary disease (COPD). European Respiratory Society consensus statement. Eur Respir J 1995; 8: 1398-1420.

2. Celli B, Snider GL, Heffner J, et al. Standards for the diagnosis and care of patients with chronic obstructive pulmonary disease. Official statement of the American Thoracic Society. Am J Respir Crit Care Med 1995; 152: S77-S120.

3. Barbera JA, Peces-Barba G, Agusti AG, et al. Guía clínica para el diagnóstico y el tratamiento de la enfermedad pulmonar obstructiva crónica. Arch Bronconeumol 2001; 37: 297-316.

4. Pauwels RA, Buist AS, Calverley PM, Jenkins CR. Hurd SS. Global strategy for the diagnosis, management, and prevention of chronic obstructive pulmonary disease. NHLBI/WHO Global Initiative for Chronic Obstructive Lung Disease (GOLD) Workshop summary. Am J Respir Crit Care Med 2001; 163 : 1256-1276.

5. Jones PW. Issues concerning health-related quality of life in COPD. Chest 1995; 107: Suppl. 5, 187S-193S.

6. Jones PW, Bosh TK. Quality of life changes in COPD patients treated with salmeterol. Am J Respir Crit Care Med 1997; 155: 1283-1289.

7. Anonymous. Skeletal Muscle Dysfunction in Chronic
Obstructive Pulmonary Disease. A statement of the American Thoracic Society and European Respiratory Society. Am J Respir Crit Care Med 1999; 159: S1S40.

8. Sala E, Roca J, Marrades RM, et al. Effects of endurance training on skeletal muscle bioenergetics in chronic obstructive pulmonary disease. Am J Respir Crit Care Med 1999; 159: 1726-1734.

9. Goldstein RS, Gort EH, Stubbing D, Avendano MA, Guyatt GH. Randomised controlled trial of respiratory rehabilitation. Lancet 1994; 344: 1394-1397.

10. Ries AL, Kaplan RM, Limberg TM, Prewitt LM. Effects of pulmonary rehabilitation on physiologic and psychosocial outcomes in patients with chronic obstructive pulmonary disease. Ann Intern Med 1995; 122: 823-832.

11. Lacasse Y, Wong E, Guyatt GH, King D, Cook DJ, Goldstein RS. Meta-analysis of respiratory rehabilitation in chronic obstructive pulmonary disease. Lancet 1996; 348: 1115-1119.

12. Clark CJ. Is pulmonary rehabilitation effective for patients with COPD? Lancet 1996; 348: 1111-1112.

13. Griffiths TL, Burr ML, Campbell IA, et al. Results at 1 year of outpatient multidisciplinary pulmonary rehabilitation: a randomised controlled trial. Lancet 2000; 355: 362-368.

14. Schols AM, Slangen J, Volovics L, Wouters EF. Weight loss is a reversible factor in the prognosis of chronic obstructive pulmonary disease. Am J Respir Crit Care Med 1998; 157: 1791-1797.

15. Landbo C, Prescott E, Lange P, Vestbo J, Almdal TP. Prognostic value of nutritional status in chronic obstructive pulmonary disease. Am J Respir Crit Care Med 1999; 160: 1856-1861.

16. Wouters EF. Nutrition and metabolism in COPD. Chest 2000; 117: 274S-280S.

17. Agustí AGN. Systemic effects of chronic obstructive pulmonary disease. In: Chadwick D, Goode JA, eds. Chronic Obstructive Pulmonary Disease: Pathogenesis to Treatment. Chichester, John Wiley \& Sons, Ltd, 2001; pp. 242-254.

18. Repine JE, Bast A, Lankhorst I and and the Oxidative Stress Study Group. Oxidative stress in chronic obstructive pulmonary disease. Am J Respir Crit Care Med 1997; 156: 341-357.

19. Rahman I, Morrison D, Donaldson K, MacNee W. Systemic oxidative stress in asthma, COPD, and smokers. Am J Respir Crit Care Med 1996; 154: 1055-1060.

20. Morrow JD, Frei B, Longmire WA, et al. Increase in circulating products of lipid peroxidation (F-isoprostanes) in smokers. $N$ Engl J Med 1995; 332: 1198-1203.

21. Praticò D, Basili S, Vieri M, Cordova C, Violi F, Fitzgerald GA. Chronic obstructive pulmonary disease is associated with an increase in urinary levels of isoprostane $\mathrm{F}_{2 \alpha}$-III, an index of oxidant stress. $\mathrm{Am}$ J Respir Crit Care Med 1998; 158: 1709-1714.

22. Burnett D, Hill SL, Chamba A, Stockley RA. Neutrophils from subjects with chronic obstructive lung disease show enhanced chemotaxis and extracellular proteolysis. Lancet 1987; 2: 1043-1046.

23. Noguera A, Batle S, Miralles C, et al. Enhanced neutrophil response in chronic obstructive pulmonary disease. Thorax 2001; 56: 432-437.

24. Noguera A, Busquets X, Sauleda J, Villaverde JM, MacNee W, Agustí AGN. Expression of adhesion 
molecules and $\mathrm{G}$ proteins in circulating neutrophils in chronic obstructive pulmonary disease. Am J Respir Crit Care Med 1998; 158: 1664-1668.

25. Noguera A, Sala E, Batle S, Iglesias J, Pons AR, Agustí AGN. Apoptosis and activation of peripheral blood neutrophils in chronic obstructive pulmonary disease. Eur Respir J 2001; 16: 74s.

26. Zheng B, Ma YC, Ostrom RS, et al. RGS-PX1, a GAP for $\mathrm{G}_{\alpha \mathrm{S}}$ and sorting nexin in vesicular trafficking. Science 2001; 294: 1939-1942.

27. Sauleda J, Garcia-Palmer FJ, Gonzalez G, Palou A, Agustí AG. The activity of cytochrome oxidase is increased in circulating lymphocytes of patients with chronic obstructive pulmonary disease, asthma, and chronic arthritis. Am J Respir Crit Care Med 2000; 161: 32-35.

28. Sauleda J, García-Palmer FJ, Wiesner R, et al. Cytochrome oxidase activity and mitochondrial gene expression in skeletal muscle of patients with chronic obstructive pulmonary disease. Am J Respir Crit Care Med 1998; 157: 1413-1417.

29. Saetta M, Di Stefano A, Turato G, et al. CD8+ T-lymphocytes in peripheral airways of smokers with chronic obstructive pulmonary disease. Am J Respir Crit Care Med 1998; 157: 822-826.

30. Jeffery PK. Structural and inflammatory changes in COPD: a comparison with asthma. Thorax 1998; 53: 129-136.

31. Saetta M. Airway inflammation in chronic obstructive pulmonary disease. Am J Respir Crit Care Med 1999; 160: S17-S20.

32. Saetta M, Baraldo S, Corbino L, et al. CD8+ve cells in the lungs of smokers with chronic obstructive pulmonary disease. Am J Respir Crit Care Med 1999; 160: 711-717.

33. Cosio MG, Guerassimov A. Chronic obstructive pulmonary disease. Inflammation of small airways and lung parenchyma. Am J Respir Crit Care Med 1999; 160: S21-S25.

34. Miller LG, Goldstein G, Murphy M, Ginns LC. Reversible alterations in immunoregulatory $\mathrm{T}$ cells in smoking. Analysis by monoclonal antibodies and flow cytometry. Chest 1982; 82: 526-529.

35. Costabel U, Bross KJ, Reuter C, Rühle K, Matthys H. Alterations in immunoregulatory $\mathrm{T}$-cell subsets in cigarrette smokers. A phenotypic analysis of bronchoalveolar and blood lymphocytes. Chest 1986; 89: 39 44.

36. Ekberg-Jansson A, Andersson B, Arva E, Nilsson O, Lofdahl CG. The expression of lymphocyte surface antigens in bronchial biopsies, bronchoalveolar lavage cells and blood cells in healthy smoking and neversmoking men, 60 years old. Respir Med 2000; 94: 264 272.

37. De Jong JW, Belt-Gritter B, Koeter GH, Postma DS. Peripheral blood lymphocyte cell subsets in subjects with chronic obstructive pulmonary disease: association with smoking, $\operatorname{IgE}$ and lung function. Respir Med 1997; 91: 67-76.

38. Amadori A, Zamarchi $\mathrm{R}$, De Silvestro $\mathrm{G}$, et al. Genetic control of the CD4/CD8 T-cell ratio in humans. Nat Med 1995; 1: 1279-1283.

39. Di Francia M, Barbier D, Mege JL, Orehek J. Tumor necrosis factor- $\alpha$ levels and weight loss in chronic obstructive pulmonary disease. Am J Respir Crit Care Med 1994; 150: 1453-1455.

40. Schols AM, Buurman WA, Staal-van den Brekel AJ,
Dentener MA, Wouters EFM. Evidence for a relation between metabolic derangements and increased levels of inflammatory mediators in a subgroup of patients with chronic obstructive pulmonary disease. Thorax 1996; 51: 819-824.

41. Yasuda N, Gotoh K, Minatoguchi S, et al. An increase of soluble Fas, an inhibitor of apoptosis, associated with progression of COPD. Respir Med 1998; 92: 993-999.

42. Agustí AGN, Noguera A, Sauleda J, Miralles C, Batle S, Busquets X. Systemic inflammation in chronic respiratory diseases. Eur Respir Mon 2003 (in press).

43. Eid AA, Ionescu AA, Nixon LS, et al. Inflammatory response and body composition in chronic obstructive pulmonary disease. Am J Respir Crit Care Med 2001; 164: 1414-1418.

44. van Eeden SF, Tan WC, Suwa T, et al. Cytokines involved in the systemic inflammatory response induced by exposure to particulate matter air pollutants (PM10). Am J Respir Crit Care Med 2001; 164: 826-830.

45. De Godoy I, Donahoe M, Calhoun WJ, Mancino J, Rogers RM. Elevated TNF- $\alpha$ production by peripheral blood monocytes of weight-losing COPD patients. Am J Respir Crit Care Med 1996; 153: 633637.

46. Celermajer DS, Adams MR, Clarkson P, et al. Passive smoking and impaired endothelium-dependent arterial dilatation in healthy young adults. N Engl J Med 1996; 334: $150-154$.

47. Raitakari OT, Adams MR, McCredie RJ, Griffiths KA, Celermajer DS. Arterial endothelial dysfunction related to passive smoking is potentially reversible in healthy young adults. Ann Intern Med 1999; 130: 578581 .

48. Fletcher C, Peto R. The natural history of chronic airflow obstruction. BMJ 1977; 1: 1645-1648.

49. Barnes PJ. Molecular genetics of chronic obstructive pulmonary disease. Thorax 1999; 54: 245-252.

50. Schols AM. Nutrition in chronic obstructive pulmonary disease. Curr Opin Pulm Med 2000; 6: 110-115.

51. Schols AMWJ, Soeters PB, Dingemans AMC, Mostert R, Frantzen PJ, Wouters EFM. Prevalence and characteristics of nutritional depletion in patients with stable COPD eligible for pulmonary rehabilitation. Am Rev Respir Dis 1993; 147: 1151-1156.

52. Engelen MP, Wouters EF, Deutz NE, Does JD, Schols AM. Effects of exercise on amino acid metabolism in patients with chronic obstructive pulmonary disease. Am J Respir Crit Care Med 2001; 163: 859-864.

53. Engelen MP, Schols AM, Does JD, Gosker HR, Deutz NE, Wouters EF. Exercise-induced lactate increase in relation to muscle substrates in patients with chronic obstructive pulmonary disease. Am J Respir Crit Care Med 2000; 162: 1697-1704.

54. Engelen MPKJ, Schols AMWJ, Heidendal GAK, Wouters EFM. Dual-energy X-ray absorptiometry in the clinical evaluation of body composition and bone mineral density in patients with chronic obstructive pulmonary disease. Am J Clin Nutr 1998; 68: 1298 1303.

55. Baarends EM, Schols AMWJ, Lichtenbelt WDVM, Wouters EFM. Analysis of body water compartments in relation to tissue depletion in clinically stable patients with chronic obstructive pulmonary disease. Am J Clin Nutr 1997; 65: 88-94.

56. Engelen MP, Schols AM, Lamers RJ, Wouters EF. 
Different patterns of chronic tissue wasting among patients with chronic obstructive pulmonary disease. Clin Nutr 1999; 18: 275-280.

57. Baarends EM, Schols AMWJ, Pannemans DLE, Westerterp KR, Wouters EFM. Total free living energy expenditure in patients with severe chronic obstructive pulmonary disease. Am J Respir Crit Care Med 1997; 155: 549-554.

58. Hugli O, Schutz Y, Fitting JW. The daily energy expenditure in stable chronic obstructive pulmonary disease. Am J Respir Crit Care Med 1996; 153: 294 300 .

59. Baarends EM, Schols AM, Westerterp KR, Wouters EF. Total daily energy expenditure relative to resting energy expenditure in clinically stable patients with COPD. Thorax 1997; 52: 780-785.

60. Ferreira IM, Brooks D, Lacasse Y, Goldstein RS. Nutritional support for individuals with COPD: a meta-analysis. Chest 2000; 117: 672-678.

61. Schols AM, Wouters EF. Nutritional abnormalities and supplementation in chronic obstructive pulmonary disease. Clin Chest Med 2000; 21: 753-762.

62. Baarends EM, Schols AMWJ, Slebos DJ, Mostert R, Janssen PP, Wouters EFM. Metabolic and ventilatory response pattern to arm elevation in patients with COPD and healthy age-matched subjects. Eur Respir $J$ 1995; 8: 1345-1351.

63. Roca J, Agustí AGN, Alonso A, Barberá JA, Rodriguez-Roisín R, Wagner PD. Effects of training on muscle $\mathrm{O}_{2}$ transport at $\mathrm{VO}_{2}$ max. J Appl Physiol 1992; 73: 1067-1076.

64. Marrades RM, Sala E, Roca J, et al. Skeletal muscle function during exercise in patients with chronic obstructive pulmonary disease. Am J Respir Crit Care Med 1997; 155: A913.

65. Wuyam B, Payen JF, Levy P, et al. Metabolism and aerobic capacity of skeletal muscle in chronic respiratory failure related to chronic obstructive pulmonary disease. Eur Respir J 1992; 5: 157-162.

66. Jakobsson P, Jorfeldt L. Nuclear magnetic resonance spectroscopy: a tool for skeletal muscle metabolic research. Eur Respir J 1992; 5: 151-154.

67. Payen JF, Wuyam B, Levy $\mathrm{P}$, et al. Muscular metabolism during oxygen supplementation in patients with chronic hypoxemia. Am Rev Respir Dis 1993; 147: 592-598.

68. Kutsuzawa T, Shioya S, Kurita D, Haida M, Ohta Y, Yamabayashi H. Muscle energy metabolism and nutritional status in patients with chronic obstructive pulmonary disease: a ${ }^{31} \mathrm{P}$ magnetic resonance study. Am J Respir Crit Care Med 1995; 152: 647-652.

69. Amoroso P, Wilson SR, Moxham J, Ponte J. Acute effects of inhaled salbutamol on the metabolic rate of normal subjects. Thorax 1993; 48: 882-885.

70. Sridhar MK. Why do patients with emphysema lose weight? Lancet 1995; 345: 1190-1191.

71. Poehlman ET, Scheffers J, Gottlieb SS, Fisher ML, Vaitekevicius P. Increased resting metabolic rate in patients with congestive heart failure. Ann Intern Med 1994; 121: 860-862.

72. Celli B, Cote C, Marin J, Montes de Oca M, Casanova C, Mendez MR. The SCORE: a new COPD staging system combining 6MWD, MRD dyspnea, FEV1 and $\mathrm{Pa}, \mathrm{O}_{2}$ as predictors of health care resources utilization (HCRU). Am J Respir Crit Care Med 2000; 161: A749.
73. Barnes PJ. Chronic obstructive pulmonary disease. $N$ Engl J Med 2000; 343: 269-280.

74. Killian KJ, Leblanc P, Martin DH, Summers E, Jones NL, Campbell EJM. Exercise capacity and ventilatory, circulatory, and symptom limitation in patients with chronic airflow limitation. Am Rev Respir Dis 1992; 146: 935-940.

75. Jones NL, Killian KJ. Mechanisms of disease: exercise limitation in health and disease. $N$ Engl J Med 2000; 343: 632-641.

76. Gosker HR, Wouters EFM, Van der Vusse GJ, Schols AMWJ. Skeletal muscle dysfunction in COPD and chronic heart failure: underlying mechanisms and therapy perspectives. Am J Clin Nutr 2000; 71: 10331047.

77. Levine S, Kaiser L, Leferovich J, Tikunov B. Cellular adaptions in the diaphragm in chronic obstructive pulmonary disease. N Engl J Med 1997; 337: 1799_ 1806.

78. Sauleda J, Gea J, Orozco-Levi M, et al. Structure and function relationships of the respiratory muscles. Eur Respir J 1998; 11: 906-911.

79. Agustí AGN, Barberá JA. Chronic pulmonary diseases: chronic obstructive pulmonary disease and idiopathic pulmonary fibrosis. Thorax 1994; 49: 924 932.

80. Roca J, Whipp BJ, Agustí AGN, et al. Clinical exercise testing with reference to lung diseases: indications, standardization and interpretation strategies. ERS Task Force on Standardization of Clinical Exercise Testing. Eur Respir J 1997; 10: 2662-2689.

81. Maltais F, Leblanc P, Simard C, et al. Skeletal muscle adaptation to endurance training in patients with chronic obstructive pulmonary disease. Am J Respir Crit Care Med 1996; 154: 442-447.

82. Maltais F, Leblanc $\mathrm{P}$, Jobin $\mathrm{J}$, et al. Intensity of training and physiologic adaptation in patients with chronic obstructive pulmonary disease. Am J Respir Crit Care Med 1997; 155: 555-561.

83. Bigard AX, Sanchez H, Birot O, Serrurier B. Myosin heavy chain composition of skeletal muscles in young rats growing under hypobaric hypoxia conditions. J Appl Physiol 2000; 88: 479-486.

84. Rennie MJ, Edwards RH, Emery PW, Halliday D, Lundholm K, Millward DJ. Depressed protein synthesis is the dominant characteristic of muscle wasting and cachexia. Clin Physiol 1983; 3: 387-398.

85. Green HJ, Sutton JR, Cymerman A, Houston CS. Operation Everest II: adaptations in human skeletal muscle. J Appl Physiol 1989; 66: 2454-2461.

86. Bigard AX, Brunet A, Guezennec CY, Monod H. Skeletal muscle changes after endurance training at high altitude. J Appl Physiol 1991; 71: 2114-2121.

87. Hughes RL, Katz H, Sahgal V, Campbell JA, Hartz R, Shields TW. Fiber size and energy metabolites in five separate muscles from patients with chronic obstructive lung disease. Respiration 1983; 44: 321-328.

88. Jakobsson P, Jorfeldt L, Brundin A. Skeletal muscle metabolites and fibre types in patients with advanced chronic obstructive pulmonary disease (COPD), with and without chronic respiratory failure. Eur Respir $J$ 1990; 3: 192-196.

89. Sauleda J, Noguera A, Busquets X, Miralles C, Villaverde JM, Agustí AGN. Systemic inflammation during exacerbations of chronic obstructive pulmonary 
disease. Lack of effect of steroid treatment. Eur Respir $J$ 1999; 14: 359s.

90. Li YP, Schwartz RJ, Waddell ID, Holloway BR, Reid MB. Skeletal muscle myocytes undergo protein loss and reactive oxygen-mediated $\mathrm{NF}-\kappa \mathrm{B}$ activation in response to tumor necrosis factor $\alpha$. FASEB J 1998; 12: 871-880.

91. Mitch WE, Goldberg AL. Mechanisms of muscle wasting. The role of the ubiquitin-proteasome pathway. $N$ Engl J Med 1996; 335: 1897-1905.

92. Petrache I, Otterbein LE, Alam J, Wiegand GW, Choi AM. Heme oxygenase-1 inhibits TNF- $\alpha$-induced apoptosis in cultured fibroblasts. Am J Physiol Lung Cell Mol Physiol 2000; 278: L312-L319.

93. Agustí AGN, Sauleda J, Miralles C, et al. Skeletal muscle apoptosis and weight loss in COPD. Am J Respir Crit Care Med 2002; 166: 485-489.

94. Adams V, Jiang $\mathrm{H}, \mathrm{Yu} \mathrm{J}$, et al. Apoptosis in skeletal myocytes of patients with chronic heart failure is associated with exercise intolerance. $\mathrm{J} \mathrm{Am} \mathrm{Coll} \mathrm{Cardiol}$ 1999; 33: 959-965.

95. Vescovo G, Volterrani M, Zennaro R, et al. Apoptosis in the skeletal muscle of patients with heart failure: investigation of clinical and biochemical changes. Heart 2000; 84: 431-437.

96. Kluck RM, Bossy-Wetzel E, Green DR, Newmeyer DD. The release of cytochrome $\mathrm{c}$ from mitochondria: a primary site for $\mathrm{Bcl}-2$ regulation of apoptosis. Science 1997; 275: 1132-1136.

97. Yang J, Liu XS, Bhalla K, et al. Prevention of apoptosis by Bcl-2: release of cytochrome c from mitochondria blocked. Science 1997; 275: 1129-1132.

98. Solary E, Dubrez L, Eymin B. The role of apoptosis in the pathogenesis and treatment of diseases. Eur Respir $J$ 1996; 9: 1293-1305.

99. Reid MB. COPD as a muscle disease. Am J Respir Crit Care Med 2001; 164: 1101-1102.

100. Reid MB, Shoji T, Moody MR, Entman ML. Reactive oxygen in skeletal muscle. II. Extracellular release of free radicals. J Appl Physiol 1992; 73: 1805 1809

101. Buck M, Chojkier M. Muscle wasting and dedifferentiation induced by oxidative stress in a murine model of cachexia is prevented by inhibitors of nitric oxide synthesis and antioxidants. EMBO J 1996; 15: 1753-1765.

102. Rabinovich RA, Ardite E, Troosters T, et al. Reduced muscle redox capacity after endurance training in patients with chronic obstructive pulmonary disease. Am J Respir Crit Care Med 2001; 164: 1114-1118.

103. Bross R, Javanbakht M, Bhasin S. Anabolic interventions for aging-associated sarcopenia. J Clin Endocrinol Metab 1999; 84: 3420-3430.

104. Woods K, Marrone A, Smith J. Programmed cell death and senescence in skeletal muscle stem cells. Ann N Y Acad Sci 2000; 908: 331-335.

105. Moncada S, Higgs A. The L-arginine-nitric oxide pathway. N Engl J Med 1993; 329: 2002-2012.

106. Kobzik L, Reid MB, Bredt DS, Stamler JS. Nitric oxide in skeletal muscle. Nature 1994; 372: 546-548.

107. Whittom F, Jobin J, Simard PM, et al. Histochemical and morphological characteristics of the vastus lateralis muscle in patients with chronic obstructive pulmonary disease. Med Sci Sports Exerc 1998; 30: 1467-1474.

108. Williams G, Brown T, Becker L, Prager M, Giroir BP. Cytokine-induced expression of nitric oxide synthase in $\mathrm{C} 2 \mathrm{C} 12$ skeletal muscle myocytes. Am J Physiol 1994; 267: R1020-R1025.

109. Gari PG, Busquets X, Morla M, Sauleda J, Agustí AGN. Upregulation of the inducible form of the nitric oxide synthase and nitrotyrosine formation in skeletal muscle of COPD patients with cachexia. Eur Respir J 2002; 20: Suppl. 38, 211s.

110. Brüne B, Von Knethen A, Sandau KB. Nitric oxide and its role in apoptosis. Eur J Pharmacol 1998; 351: 261-272.

111. Lanone S, Mebazaa A, Heymes C, et al. Muscular contractile failure in septic patients: role of the inducible nitric oxide synthase pathway. Am J Respir Crit Care Med 2000; 162: 2308-2315.

112. Cucina A, Sapienza P, Corvino V, et al. Nicotineinduced smooth muscle cell proliferation is mediated through bFGF and TGF- $\beta 1$. Surgery 2000; 127: 316322

113. Broal P. Main features of structure and function. In: Broal P, ed. The Central Nervous System. New York, NY, Oxford University Press, 1992; pp. 5-50.

114. Silverman EK, Speizer FE, Weiss ST, et al. Familial aggregation of severe, early-onset COPD: candidate gene approaches. Chest 2000; 117: 273S-274S.

115. Silverman EK, Chapman HA, Drazen JM, et al. Genetic epidemiology of severe, early-onset chronic obstructive pulmonary disease - risk to relatives for airflow obstruction and chronic bronchitis. Am J Respir Crit Care Med 1998; 157: 1770-1778.

116. Williams AG, Rayson MP, Jubb M, et al. The ACE gene and muscle performance. Nature 2000; 403: 614.

117. van Suylen RJ, Wouters EF, Pennings HJ, et al. The DD genotype of the angiotensin converting enzyme gene is negatively associated with right ventricular hypertrophy in male patients with chronic obstructive pulmonary disease. Am J Respir Crit Care Med 1999; 159: 1791-1795.

118. Onder G, Penninx BW, Balkrishnan R, et al. Relation between use of angiotensin-converting enzyme inhibitors and muscle strength and physical function in older women: an observational study. Lancet 2002; 359: $926-930$

119. Guttridge DC, Mayo MW, Madrid LV, Wang CY, Baldwin AS. NF- $\kappa \mathrm{B}$-induced loss of MyoD messenger RNA: possible role in muscle decay and cachexia. Science 2000; 289: 2363-2366.

120. Muscat GE, Dressel U. Not a minute to waste. Nat Med 2000; 6: 1216-1217.

121. Lockhart DJ, Winzeler EA. Genomics, gene expression and DNA arrays. Nature 2000; 405: 827-836.

122. Busquets X, Agustí AGN. Chip genético (DNAarray): el futuro ya está aquí!. Arch Bronconeumol 2001; 37: 394-396.

123. Busquets X, MacFarlane N, Gari PG, Morla M, Sauleda J, Agustí AGN. Oligonucleotide array analysis (DNA-chip) of gene expression in skeletal muscle of COPD. Eur Respir J 2002; 20: Suppl. 38, 496s.

124. Kamischke A, Kemper DE, Castel MA, et al. Testosterone levels in men with chronic obstructive pulmonary disease with or without glucocorticoid therapy. Eur Respir J 1998; 11: 41-45.

125. Casaburi R. Rationale for anabolic therapy to facilitate rehabilitation in chronic obstructive pulmonary disease. Baillieres Clin Endocrinol Metab 1998; 12: 407-418.

126. Creutzberg EC, Wouters EF, Vanderhoven-Augustin IM, Dentener MA, Schols AM. Disturbances in leptin 
metabolism are related to energy imbalance during acute exacerbations of chronic obstructive pulmonary disease. Am J Respir Crit Care Med 2000; 162: 12391245.

127. Schols AM, Creutzberg EC, Buurman WA, Campfield LA, Saris WH, Wouters EF. Plasma leptin is related to proinflammatory status and dietary intake in patients with chronic obstructive pulmonary disease. Am J Respir Crit Care Med 1999; 160: 1220 1226.

128. Takabatake $\mathrm{N}$, Nadamura $\mathrm{H}$, Abe $\mathrm{S}$, et al. Circulating leptin in patients with chronic obstructive pulmonary disease. Am J Respir Crit Care Med 1999; 159: 12151219.

129. Ebashi S, Endo M. Calcium ion and muscle contraction. Prog Biophys Mol Biol 1968; 18: 123-183.

130. Fiaccadori E, Coffrini E, Fracchia C, Rampulla C, Montagna T, Borghetti A. Hypophosphatemia and phosphorus depletion in respiratory and peripheral muscles of patients with respiratory failure due to COPD. Chest 1994; 105: 1392-1398.

131. Molloy DW, Dhingra S, Solven F, Wilson A, McCarthy DS. Hypomagnesemia and respiratory muscle power. Am Rev Respir Dis 1984; 129: 497-498.

132. Brown RS. Potassium homeostasis and clinical implications. Am J Med 1984; 77: 3-9.

133. Gayan-Ramirez G, Vanderhoydonc F, Verhoeven G, Decramer M. Acute treatment with corticosteroids decreases IGF-1 and IGF-2 expression in the rat diaphragm and gastrocnemius. Am J Respir Crit Care Med 1999; 159: 283-289.

134. Decramer M, De Bock V, Dom R. Functional and histologic picture of steroid-induced myopathy in chronic obstructive pulmonary disease. Am J Respir Crit Care Med 1996; 153: 1958-1964.

135. Decramer M, Lacquet LM, Fagard R, Rogiers P. Corticosteroids contribute to muscle weakness in chronic airflow obstruction. Am J Respir Crit Care Med 1994; 150: 11-16.

136. Dekhuijzen PNR, Decramer M. Steroid-induced myopathy and its significance to respiratory disease: a known disease rediscovered. Eur Respir J 1992; 5: 997-1003.

137. Sin DD, Tu JV. Inhaled corticosteroids and the risk of mortality and readmission in elderly patients with chronic obstructive pulmonary disease. Am J Respir Crit Care Med 2001; 164: 580-584.

138. Harper R, Brazier JE, Waterhouse JC, Walters SJ, Jones NM, Howard P. Comparison of outcome measures for patients with chronic obstructive pulmonary disease (COPD) in an outpatient setting. Thorax 1997; 52: 879-887.

139. Rennard S, Carrera M, Agustí AG. Management of chronic obstructive pulmonary disease: are we going anywhere? Eur Respir J 2000; 16: 1035-1036.

140. Bathon JM, Martin RW, Fleischmann RM, et al. A comparison of etanercept and methotrexate in patients with early rheumatoid arthritis. $N$ Engl J Med 2000; 343: 1586-1593.

141. Lipsky PE, van der Heijde DM, St Clair EW, et al. Infliximab and methotrexate in the treatment of rheumatoid arthritis. N Engl J Med 2000; 343: 1594 1602.

142. Lovell DJ, Giannini EH, Reiff A, et al. Etanercept in children with polyarticular juvenile rheumatoid arthritis. $N$ Engl J Med 2000; 342: 763-769.

143. Pisetsky DS. Tumor necrosis factor blockers in rheumatoid arthritis. $N$ Engl J Med 2000; 342: 810811.

144. O'Dell JR. Anticytokine therapy - a new era in the treatment of rheumatoid arthritis? N Engl J Med 1999; 340: $310-312$.

145. Wienblatt ME, Kremer JM, Bankhurst AD, et al. A trial of etanercept, a recombinant tumor necrosis factor receptor: $\mathrm{Fc}$ fusion protein, in patients with rheumatoid arthritis receiving methotrexate. $N$ Engl J Med 1999; 340: 253-259.

146. Vescovo G, Zennaro R, Sandri M, et al. Apoptosis of skeletal muscle myofibers and interstitial cells in experimental heart failure. J Mol Cell Cardiol 1998; 30: 2449-2459.

147. Agustí AGN, Cotes J, Wagner PD. Responses to exercise in lung diseases. Eur Respir Mon 1997; 2: 32 50.

148. Colucci WS. Apoptosis in the heart. $N$ Engl J Med 1996; 335: 1224-1226.

149. Narula J, Haider N, Virmani R, et al. Apoptosis in myocytes in end-stage heart failure. $N$ Engl $\mathrm{J} \mathrm{Med}$ 1996; 335: 1182-1189.

150. Olivetti G, Abbi R, Quani F, et al. Apoptosis in the failing human heart. N Engl J Med 1997; 336: 11311141.

151. Williams RS. Apoptosis and heart failure. $N$ Engl $J$ Med 1999; 341: 759-760.

152. Dinh-Xuan AT, Higenbottam TW, Clelland CA, et al. Impairment of endothelium-dependent pulmonaryartery relaxation in chronic obstructive lung disease. $N$ Engl J Med 1991; 324: 1539-1547.

153. Celermajer DS, Sorensen KE, Gooch VM, et al. Non-invasive detection of endothelial dysfunction in children and adults at risk of atherosclerosis. Lancet 1992; 340: 1111-1115.

154. Howes TQ, Deane CR, Levin GE, Baudouin SV, Moxham J. The effects of oxygen and dopamine on renal and aortic blood flow in chronic obstructive pulmonary disease with hypoxemia and hypercapnia. Am J Respir Crit Care Med 1995; 151: 378-383.

155. Baudouin SV, Bott J, Ward A, Deane C, Moxham J. Short term effect of oxygen on renal haemodynamics in patients with hypoxaemic chronic obstructive airways disease. Thorax 1992; 47: 550-554.

156. Mathur R, Cox IJ, Oatridge A, Shephard DT, Shaw RJ, Taylor-Robinson SD. Cerebral bioenergetics in stable chronic obstructive pulmonary disease. Am J Respir Crit Care Med 1999; 160: 1994-1999.

157. Hochachka PW, Clark CM, Brown WD, et al. The brain at high altitude: hypometabolism as a defense against chronic hypoxia. J Cereb Blood Flow Metab 1994; 14: 671-679.

158. Borak J, Sliwinski P, Piasecki Z, Zielinski J. Psychological status of COPD patients on long term oxygen therapy. Eur Respir J 1991; 4: 59-62.

159. Light RW, Merrill EJ, Despars JA, Gordon GH, Mutalipassi LR. Prevalence of depression and anxiety in patients with COPD. Relationship to functional capacity. Chest 1985; 87: 35-38.

160. Wagena EJ, Huibers MJ, van Schayck CP. Antidepressants in the treatment of patients with COPD: possible associations between smoking cigarettes, COPD and depression. Thorax 2001; 56: 587-588.

161. Tracey KJ, Cerami A. Tumor necrosis factor: a pleiotropic cytokine and therapeutic target. Annu Rev Med 1994; 45: 491-503.

162. Holden RJ, Pakula IS, Mooney PA. An immunolo- 
gical model connecting the pathogenesis of stress, depression and carcinoma. Med Hypotheses 1998; 51: 309-314.

163. Worrall NK, Chang K, Suau GM, et al. Inhibition of inducible nitric oxide synthase prevents myocardial and systemic vascular barrier dysfunction during early cardiac allograft rejection. Circ Res 1996; 78: 769-779.

164. Takabatake N, Nakamura H, Minamihaba O, et al. A novel pathophysiologic phenomenon in cachexic patients with chronic obstructive pulmonary disease: the relationship between the circadian rhythm of circulating leptin and the very low-frequency component of heart rate variability. Am J Respir Crit Care Med 2001; 163: 1314-1319.

165. Incalzi RA, Caradonna $\mathrm{P}$, Ranieri $\mathrm{P}$, et al. Correlates of osteoporosis in chronic obstructive pulmonary disease. Respir Med 2000; 94: 1079-1084.

166. Gross NJ. Extrapulmonary effects of chronic obstructive pulmonary disease. Curr Opin Pulm Med 2001; 7: 84 92.

167. Nishimura Y, Nakata H, Matsubara M, Maeda H, Yokoyama $\mathrm{H}$. Bone mineral loss in patients with chronic obstructive pulmonary disease. Nihon Kyobu Shikkan Gakkai Zasshi 1993; 31: 1548-1552.

168. Goldstein MF, Fallon JJ Jr, Harning R. Chronic glucocorticoid therapy-induced osteoporosis in patients with obstructive lung disease. Chest 1999; 116: 1733-1749.

169. McEvoy CE, Ensrud KE, Bender E, et al. Association between corticosteroid use and vertebral fractures in older men with chronic obstructive pulmonary disease. Am J Respir Crit Care Med 1998; 157: 704-709. 